\title{
IN VITRO STUDY OF THE PULP CHAMBER TEMPERATURE RISE DURING LIGHT-ACTIVATED BLEACHING
}

\author{
Thaise Graciele CARRASCOํㅗㅇ Laise Daniela CARRASCO-GUERISOLI ${ }^{1}$, Izabel Cristina FRÖNER ${ }^{2}$
}

1- DDS, MSc, Graduate student, Department of Restorative Dentistry, Dental School of Ribeirão Preto, University of São Paulo, Ribeirão Preto, SP, Brazil.

2- DDS, MSc, PhD, Associate Professor, Department of Restorative Dentistry, Dental School of Ribeirão Preto, University of São Paulo, Ribeirão Preto, SP, Brazil.

Corresponding address: Profa. Dra. Izabel Cristina Fröner - Departamento de Odontologia Restauradora - Faculdade de Odontologia de Ribeirão Preto - Universidade de São Paulo - Avenida do Café, s/nº- Monte Alegre - 14040-904 Ribeirão Preto, SP, Brasil.

Phone: +55 16 3602-4055. Fax: + 5516 3602-4781. e-mail: froner@forp.usp.br

Received: October 22, 2007 - Modification: March 4, 2008 - Accepted: April 14, 2008

\begin{abstract}
$T_{\text {his }}$

Ihis study evaluated in vitro the pulp chamber temperature rise induced by the light-activated dental bleaching technique using different light sources. The root portions of 78 extracted sound human mandibular incisors were sectioned approximately $2 \mathrm{~mm}$ below the cementoenamel junction. The root cavities of the crowns were enlarged to facilitate the correct placing of the sensor into the pulp chamber. Half of specimens $(n=39)$ was assigned to receive a $35 \%$ hydrogen peroxide gel on the buccal surface and the other halt $(n=39)$ not to receive the bleaching agent. Three groups $(n=13)$ were formed for each condition (bleach or no bleach) according to the use of 3 light sources recommended for dental bleaching: a light-emitting diode (LED)laser system, a LED unit and a conventional halogen light. The light sources were positioned perpendicular to the buccal surface at a distance of $5 \mathrm{~mm}$ and activated during $30 \mathrm{~s}$. The differences between the initial and the highest temperature readings for each specimen were obtained, and, from the temperature changes, the means for each specimen and each group were calculated. The values of temperature rise were compared using Kruskal-Wallis test at $1 \%$ significance level. Temperature rise varied significantly depending on the light-curing unit, with statistically significant differences $(\mathrm{p}<0.01)$ among the groups. When the bleaching agent was not applied, the halogen light induced the highest temperature rise $\left(2.38 \pm 0.66^{\circ} \mathrm{C}\right)$. The LED unit produced the lowest temperature increase $\left(0.29 \pm 0.13^{\circ} \mathrm{C}\right)$; but there was no significant difference between LED unit and LEDlaser system $\left(0.35 \pm 0.15^{\circ} \mathrm{C}\right)(\mathrm{p}>0.01)$. When the bleaching agent was applied, there were significant differences among groups $(\mathrm{p}<0.01)$ : halogen light induced the highest temperature rise $\left(1.41 \pm 0.64^{\circ} \mathrm{C}\right)$, and LED-laser system the lowest $\left(0.33 \pm 0.12^{\circ} \mathrm{C}\right)$; however, there was no difference between LED-laser system and LED unit $\left(0.44 \pm 0.11^{\circ} \mathrm{C}\right)$. LED and LED-laser system did not differ significantly from each other regardless the temperature rise occurred with or without bleaching agent application. It may be concluded that during light-activated tooth bleaching, with or without the bleaching agent, halogen light promoted higher pulp chamber temperature rise than LED unit and LED-laser system. The tested light-curing units provided increases in the pulp chamber temperature that were compatible with pulpal health.
\end{abstract}

Key words: Tooth bleaching. Dental pulp cavity.

\section{INTRODUCTION}

Influenced by the most diverse social contexts, physical appearance has become a great concern of people, which include a perfect smile with white and lined up teeth. In view of this, tooth bleaching, an esthetic, more conservative and less expensive procedure, has been constantly requested by patients?

Hydrogen peroxide, sodium perborate and carbamide peroxide are generally used for bleaching procedure ${ }^{25}$, being effective for bleaching teeth. However, side effects, such as changes in the tooth structure ${ }^{19}$, microleakage in restorations ${ }^{7}$, external root resorption and pulpal irritation ${ }^{18}$ have been reported. The in-office technique using bleaching agents at high concentrations associated with thickening, catalysts or light-activated ${ }^{11}$ agents is faster and more effective, but requires the use of heat or light source for activation of the hydrogen peroxide ${ }^{4}$.

In an attempt to achieve the bleaching of several types of tooth stains, an external heat source was associated to hydrogen peroxide in discolored teeth ${ }^{6,14}$. The activation of a bleaching agent by thermocatalytic technique has been questioned due its deleterious effects on tooth structure ${ }^{23}$. Destructive effects to the pulp due to temperature rise during bleaching procedure has been described ${ }^{8}$, showing cellular damage, with enzymatic inactivation and consequent 
rupture $^{3}$. However, histological aspects did not demonstrate harmful effects on pulpal tissue when hydrogen peroxide and heat were used for vital bleaching ${ }^{6}$. Consequences of direct applications of heat on tooth structures may be mild, but may also be extremely severe, leading to irreversible pulp damage ${ }^{28}$.

In recent bleaching systems, light-curing units of composite resins, conventional halogen light, lasers and LEDs (light-emitting diodes) ${ }^{11}$ are employed for activating the 35 to $50 \%$ hydrogen peroxide-based bleaching agents. Halogen light produces high heat generation. Its thermal effects may result in an excessive heating of pulpal tissue, increasing the incidence of postoperative sensitivity ${ }^{1,13}$. As type of concentrated luminous energy, laser has revolutionized the use of light sources, being proved efficient in activating bleaching agents ${ }^{17}$. LEDs are also able to produce light in a specific wavelength and may be employed for accelerating the chemical reaction of the bleaching material ${ }^{21}$. Light-curing units that produce high energy induce significantly higher intra-pulpal temperature change ${ }^{26}$. Temperature elevations of $5.6^{\circ} \mathrm{C}$ or greater cause pulpal damage and may result in necrosis in $15 \%$ of cases, depending on pulp health its physiological response capacity $^{29}$.

In light-activated bleaching procedures, there is great concern about the heat generated by the light source, which may cause pulp necrosis. Previous studies using different light sources demonstrated that differences in temperature changes depend on the type of light employed ${ }^{1,8,20}$, and may be critical ${ }^{1,8,12,21}$ or not ${ }^{10,20}$ for pulpal health.

The purpose of this in vitro study was to evaluate the pulp chamber temperature rise induced by different light sources (a conventional halogen light, a LED-laser system and a LED unit) using or not a bleaching agent.

\section{MATERIALAND METHODS}

In this study model, the crowns of human teeth were submitted to 35\% hydrogen peroxide bleaching (Whiteness HP, FGM Produtos Odontológicos Ltda, Joinvile, PR, Brazil) activated by different light sources (Table 1). The response variable was pulp chamber temperature rise measured by a pulp chamber sensor, obtaining the average for each specimen and each group.

For such purpose, 78 extracted human mandibular incisors with similar pulp chamber morphology, free of caries, calcifications and restorations and stored in saline at $9^{\circ} \mathrm{C}$ were selected after evaluation under x10 stereoscopic magnification and radiographic examination. The use of extracted human teeth was approved by the Research Ethics Committee of the Dental School of Ribeirão Preto, University of São Paulo (Process \#2004.1.787.58.8).

The root portions of the teeth were sectioned with a double-faced diamond saw (KG Sorensen Indústria e Comércio Ltda, São Paulo, SP, Brazil) approximately $2 \mathrm{~mm}$ below the cementoenamel junction in a buccolingual direction and perpendicular to the long axis of the teeth. The root cavities of the crowns were enlarged with \#12, 14 and 16 Batt burs and \#6 Gates Glidden burs (Dyna Endodontic Instruments, Bourges, France) to facilitate the correct positioning of the thermocouple into the pulp chamber. During preparation, cavities were irrigated with 10 $\mathrm{mL}$ of $1 \%$ sodium hypochlorite solution. Thereafter, specimens were immersed in the same solution for $24 \mathrm{~h}$ to remove the remnant pulpal tissue. After this, specimens were rinsed for 1 hour in running water and let to dry at room temperature during $6 \mathrm{~h}$.

Half of specimens $(n=39)$ was assigned to use of the $35 \%$ hydrogen peroxide gel and the other halt $(n=39)$ not to receive the bleaching agent. Three groups $(n=13)$ were formed for each condition (bleach or no bleach) according to three light sources used in the study.

The temperature rise was measured in the pulp chamber using a thermocouple wire (Termopar Digital Multimeter, Tektronix DMM 916, USA). Specimens were positioned in an acrylic apparatus with an opening for inserting the wire into the cavity and a mark to determine the correct distance of the light source. The thermocouple wire was located in the pulp chamber in contact with the buccal wall and the specimen was the properly fixed (Figure 1). During application, light sources were positioned perpendicular to the buccal surface at a distance of $5 \mathrm{~mm}$ for $30 \mathrm{~s}^{4}$. The LEDlaser system employed has an association of two types of

TABLE 1- Light sources evaluated in the study

\begin{tabular}{cccc}
\hline Brand & Manufacturer & Type of light & $\begin{array}{c}\text { Power } \\
\text { Application } \\
\text { time(s) }\end{array}$ \\
\hline $\begin{array}{c}\text { Brightness } \\
\text { Laser Light }\end{array}$ & $\begin{array}{c}\text { Kondortech Equipamentos } \\
\text { Odontológicos Ltda, São } \\
\text { Carlos, SP, Brazil }\end{array}$ & LED-laser System & $40 \mathrm{~mW}$ \\
Ultrablue & DMC Indústria e Comércio & LED & $300 \mathrm{~mW}$ \\
Ultralux & Ltda, São Paulo, SP, Brazil & & 30 \\
& Dabi Atlante Ltda, Ribeirão & Conventional halogen light & $450 \mathrm{~mW}$ \\
\hline
\end{tabular}




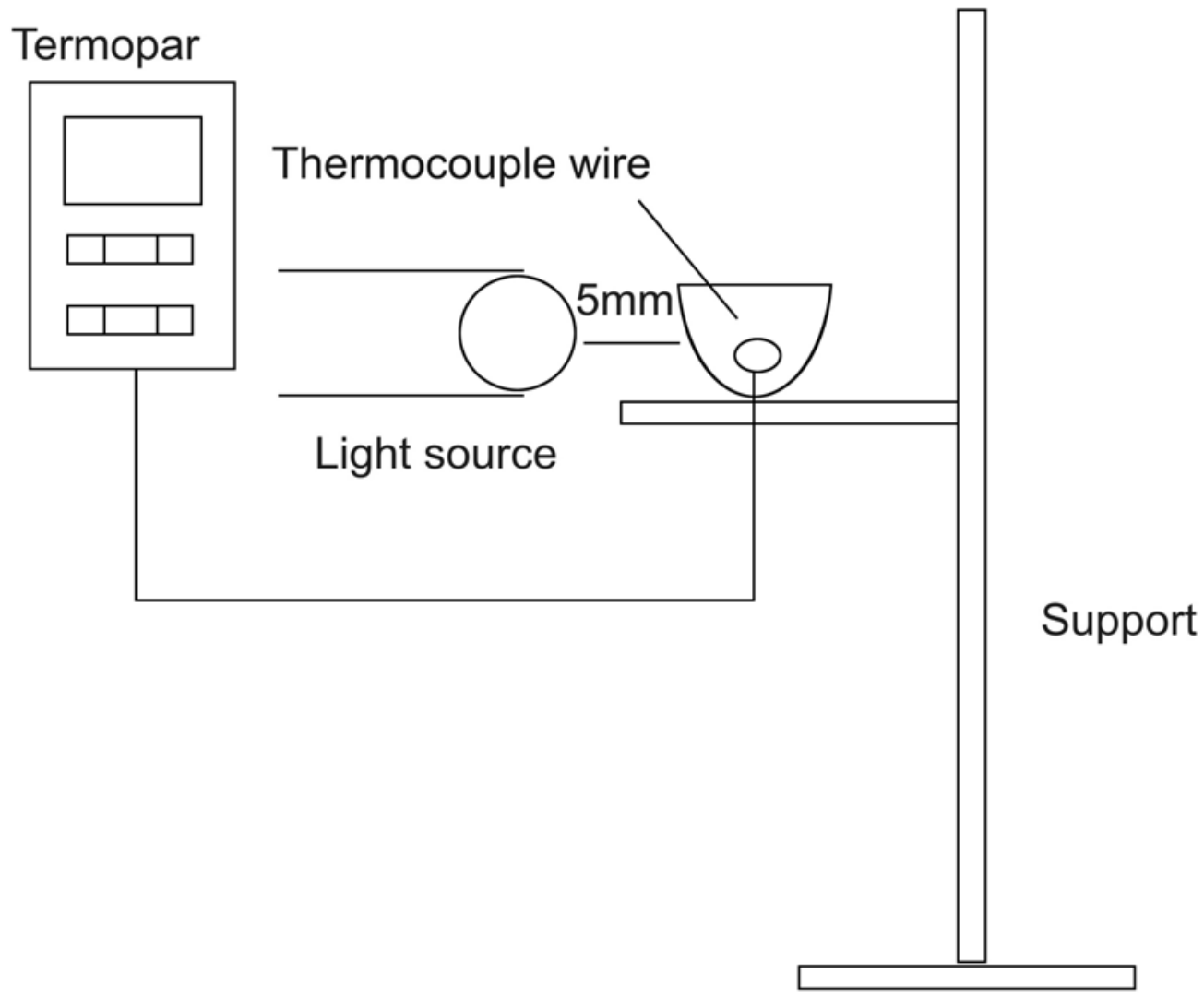

FIGURE 1- Schematic drawing of the experimental set up showing the temperature measurement

light - a LED (470 nm, 8 LEDs, 4000 milicandelas) and a therapeutic diode laser $(790 \mathrm{~nm}, 40 \mathrm{~mW})$, which are emitted simultaneously. Three applications of each light source were performed on each specimen at room temperature $\left(25^{\circ} \mathrm{C}\right)$ with or without the presence of the bleaching gel on the tooth surface waiting sufficient time between applications for the specimens to return to room temperature. Room temperature was checked by referring to the thermocouple reading. The 35\% hydrogen peroxide bleaching gel was prepared according to the manufacturer's instructions and applied on buccal surface of the specimen to produce a uniform layer approximately $1 \mathrm{~mm}$ thickness. The gel was removed and a fresh mix of gel placed for each subsequent temperature reading.

The mean of the difference between the baseline and the highest temperature was calculated for each specimen and each group. Data were submitted to statistical analysis by Kruskal-Wallis test for intergroup comparisons at $1 \%$ significance level.

\section{RESULTS}

The means and standard deviation of the temperature rise in the pulp chambers induced by the light sources with or without gel are shown in Table 2. Temperature increased significantly depending on the light-curing unit used. When the bleaching agent was not applied, the halogen light induced the highest temperature rise $\left(2.38 \pm 0.66^{\circ} \mathrm{C}\right)(\mathrm{p}<0.01)$. The LED unit produced the lowest temperature increase $\left(0.29 \pm 0.13^{\circ} \mathrm{C}\right)$; but there was no significant difference $(\mathrm{p}>0.01)$ between LED unit and LED-laser system $\left(0.35 \pm 0.15^{\circ} \mathrm{C}\right)$.

When the bleaching agent was applied, there were significant differences between groups. Halogen light induced the highest temperature rise $\left(1.41 \pm 0.64^{\circ} \mathrm{C}\right)(\mathrm{p}<0.01)$, and LED-laser system the lowest increase of temperature $\left(0.33 \pm 0.12^{\circ} \mathrm{C}\right)(\mathrm{p}<0.01)$. However, there was no $(\mathrm{p}>0.01)$ difference between LED-laser system and LED unit $\left(0.44 \pm 0.11^{\circ} \mathrm{C}\right)$. ED and LED-laser system did not differ

TABLE 2- Means ( \pm SD) of pulp chamber temperature rise $\left({ }^{\circ} \mathrm{C}\right)$ induced by the light sources evaluated in the study

\begin{tabular}{lccc}
\hline Light source & Without bleaching gel & With bleaching gel & \\
\hline Brightness & $0.35 \pm 0.15$ & $0.33 \pm 0.12$ & $\mathrm{~A}$ \\
Ultrablue & $0.29 \pm 0.13$ & $0.44 \pm 0.11$ & $\mathrm{~A}$ \\
Ultralux & $2.38 \pm 0.66$ & $1.41 \pm 0.64$ & $\mathrm{~B}$ \\
\hline
\end{tabular}

Different letters indicate statistically significant difference $(\alpha=0.01)$ 
significantly from each other regardless the temperature rise occurred with or without bleaching agent application..

\section{DISCUSSION}

Light activation has been empirically used to catalyze the decomposition of hydrogen peroxide and increase the bleaching speed ${ }^{11}$. However, light-activated bleaching procedures may raise pulp chamber temperature ${ }^{1}$.

This in vitro study evaluated the pulp chamber temperature rise induced by three different light sources employed in light-activated tooth bleaching. The highest temperature rise was recorded using the halogen light and the lowest one using the LED unit. This result is in accordance with the findings of previous studies which concluded that LED unit induces a lower temperature rise during light curing of composite resins ${ }^{12}$ and bleaching procedures $^{8,24}$. However, there were no significant differences between LED unit and LED-laser system with or without the bleaching gel. When compared to the LEDs, halogen light induces higher pulp chamber temperature rises during light activation of bleaching agents ${ }^{1}$.

Similar to halogen light, LED light is a divergent and noncoherent light source. However, LED presents a thinner emission spectral, has higher output and does not produce heat, which allow its use in therapies without significant risks ${ }^{27}$ and validate this light source as an alternative to the conventional light-curing units. The type of light employed affects significantly the intra-pulpal temperature rise. Halogen light and plasma arc lamp induce higher intra-pulpal temperature rises when compared to argon laser ${ }^{1,5}$. Diode laser is an effective method for tooth bleaching, but it has demonstrated a significant pulp chamber temperature rise ${ }^{21}$ compared to plasma arc lamp, halogen light, xenon lamp, and $\mathrm{LED}^{8,20,22}$. When heat is used in vital biological tissues, a regional histological pulp response is observed ${ }^{15,29}$. In the present study, pulp chamber temperature rise was evaluated, but no histological evaluations were performed.

The effect of pulp chamber temperature rise in bleaching procedures has been investigated. Zach and Cohen ${ }^{29}$ (1965) reported pulp irreversibility in $15 \%$ of the teeth of rhesus monkeys with a temperature elevation of $5.6^{\circ} \mathrm{C}, 60 \%$ for an elevation of $11^{\circ} \mathrm{C}$, and $100 \%$ for a temperature elevation of $16.6^{\circ} \mathrm{C}$, showing a potential histopathological alteration in the pulp tissue when the temperature exceeds $5.6^{\circ} \mathrm{C}$. However, Baldissara, et al. ${ }^{2}$ (1997) reported that an intrapulpal temperature rise of $8.9^{\circ} \mathrm{C}$ to $14.7^{\circ} \mathrm{C}$ in humans does not induce pulpal pathology. The values of temperature rise obtained in this study are not critical for pulp health. Eriksson, et al. ${ }^{9}(1982)$ found that $42^{\circ} \mathrm{C}$ might be a critical temperature to the pulp when sustained for $1 \mathrm{~min}$. Nyborg and Brännström ${ }^{15}$ (1968) demonstrated that an external heat application for $30 \mathrm{~s}$ causes severe histopathological changes, but there was necrosis only in $10 \%$ of the cases. As there is no agreement about which is the lowest value of pulp chamber temperature rise that would cause pulp damage it is rational to use a light source that minimizes possible iatrogenic problems during clinical treatments ${ }^{1}$. In the present study, the light sources were activated for $30 \mathrm{~s}$. During this time, with or without the gel, respectively, halogen light resulted in an pulp chamber temperature rise of $1.41^{\circ} \mathrm{C}$ and $2.38^{\circ} \mathrm{C}$, while LED increased $0.44^{\circ} \mathrm{C}$ and $0.29^{\circ} \mathrm{C}$, and LEDlaser $0.33^{\circ} \mathrm{C}$ and $0.35^{\circ} \mathrm{C}$. The temperature rose significantly depending on the light source used. There were significant differences among the groups. With or without application of the bleaching gel, halogen light provided a higher temperature rise, while LED unit and LED-laser system were not different and induced lower pulp chamber temperature rise. A previous study has shown that the use of bleaching gel is able to offer a protective insulating layer against the pulp chamber temperature increase that results from the use of light-activated bleaching units ${ }^{21}$. In this study, there was a decrease in the temperature when the bleaching gel was used for the LED-laser and halogen light, unlike the LED unit, which promoted pulp chamber temperature increase. However, no significant differences were found with or without the presence of the bleaching gel. The maximum values of temperature rise recorded for all light sources evaluated in the study were not considered critical to pulp integrity. However, the temperature values measured in this study cannot be directly applied for temperature changes in vivo. The reason is that the method accomplished in this study does not consider the heat conduction within the tooth during in situ bleaching material activation due to the effect of blood circulation in the pulp chamber ${ }^{16}$. A shortfall interfering with the results of this study is that this type of experiment cannot be conducted in vivo. Even an in vivo study on teeth undergoing root canal therapy would be less representative of the clinical situation than the present in vitro model because in a clinical study the thermocouple would not be totally enclosed into the dental tissues as it would be introduced through a coronal access cavity and there would be heat loss to the surrounding air introducing a potentially significant error ${ }^{21}$. Therefore, it is important to know the light sources being employed, and their advantages in order to have a suitable perspective in esthetic dentistry.

\section{CONCLUSION}

According to the results obtained in this study and within the limitations of an in vitro investigation, it may be concluded that during light-activated tooth bleaching, with or without use of bleaching agent, halogen light promoted higher pulp chamber temperature rise than LED unit and LED-laser system. For all light sources evaluated, the maximum pulp chamber temperature rises recorded are not considered as critical for pulp tissue.

\section{ACKNOWLEDGEMENTS}

The authors would like to thank 'FGM Produtos Odontológicos Ltda', Joinvile, SC, Brazil, for providing the bleaching gel used in this study and Mr. Reginaldo Santana 
for his technical assistance during the experimental phase of this study.

\section{REFERENCES}

1- Baik JW, Rueggeberg FA, Liewehr FR. Effect of light-enhanced bleaching on in vitro surface and intrapulpal temperature rise. J Esthet Restor Dent. 2001;13:370-8.

2- Baldissara P, Capatano S, Scotti R. Clinical and histological evaluation of thermal injury thresholds in human teeth: a preliminary study. J Oral Rehabil. 1997;24:791-801.

3- Bowles WH, Thompson LR. Vital bleaching: the effects of heat and hydrogen peroxide on pulpal enzymes. J Endod. 1986;12:10812 .

4- Brugnera AJr, Zanin F. Clareamento dental com luz-laser. São Paulo: Editora Santos; 2004.

5- Cobb DS, Dederich DN, Gardner TV. In vitro temperature change at the dentin/pulpal interface by using conventional visible light versus argon laser. Lasers Surg Med. 2000;26:386-97.

6- Cohen SC. Human pulpal response to bleaching procedures on vital teeth. J Endod. 1979;5:134-8.

7- Crim GA. Prerestorative bleaching: effect on microleakage of Class V cavities. Quintessence Int. 1992;23:823-5.

8- Eldeniz AU, Usumez A, Usumez S, Ozturk N. Pulpal temperature rise during ligth-activated bleaching. J Biomed Mater Res B Appl Biomater. 2005;72:254-9.

9- Erikkson A, Albrektsson T, Grane B, McQueen D. Thermal injury to bone. A vital microscopic description of heat effects. Int J Oral Surg. 1982;11:115-21.

10- Hannig M, Bott B. In-vitro pulp chamber temperature rise during composite resin polymerization with various light-curing sources. Dent Mater J. 1999;15:275-81.

11- Hein DK, Ploeger BJ, Hartup JK, Wagstaff RS, Palmer TM, Hansen LD. In-office vital tooth bleaching - what do lights add? Compend Contin Educ Dent. 2003;24:340-52.

12- Knezevi A, Tarle Z, Meniga A, Utalo J, Pichler G. Influence of light intensity from different curing units upon composite temperature rise. J Oral Rehabil. 2005;32:362-70.

13- Loney RW, Price RBT. Temperature transition of high-output light-curing units through dentin. Oper Dent. 2001;26:516-20.

14- Murrin JR, Barkmeier WM. Chemical treatment of endemic dental fluorosis. Quintessence Int Dent Dig. 1982;13:363-9.

15- Nyborg H, Brännström M. Pulp reaction to heat. J Prosthet Dent. 1968;19:605-12.

16- Raab WHM. Temperature changes in pulpal microcirculation. Proc Finn Dent Soc. 1992;88:469-79.

17- Reyto R. Laser tooth whitening. D Clin North Am. 1998;42:75562

18- Robertson WD, Melfi RC. Pulpal response to vital bleaching procedures. J Endod. 1980;6:645-9.

19- Rotstein I, Dankner E, Goldman A, Heling I, Stabholz A, Zalkind M. Histochemical analysis of dental hard tissues following bleaching. J Endod. 1996;22:23-5.
20- Sulieman M, Addy M, Rees JS. Surface and intra-pulpal temperature rises during tooth bleaching: an in vitro study. Br Dent J. 2005;199:3740 .

21- Sulieman M, Rees JS, Addy M. Surface and pulp chamber temperature rises during tooth bleaching using a diode laser: a study in vitro. Br Dental J. 2006;200:631-4.

22- Tarle Z, Meniga A, Knezevic A, Sutalo J, Ristic M. Composite conversion and temperature rise using a conventional, plasma arc, and a experimental blue LED curing unit. J Oral Rehabil. 2002;29:6627 .

23- Trope M. Cervical root resorption. J Am Dent Assoc. 1997;128:56-9.

24- Usumez A, Ozturk N. Temperature increase during resin cement polymerization under a ceramic restoration: effect of type of curing units. Int J Prosthodont. 2004;17:200-4.

25- Uysal T, Basciftci F, Usumez S, Sari Z, Büyükerkmen A. Can previously bleached teeth be bonded safety? Am J Orthod Dentofacial Orthop. 2003;123:628-32.

26- Weerakoon AT, Meyers IA, Symons AL, Walsh LJ. Pulpal heat changes with newly developed resin photopolymerization systems. Aust Endod J. 2002;28:108-11.

27- Whelan HT, Smits RL, Whelan NT, Turner SG, Margolis DA, Cevenini V, Stinson H, Ignatius R, Martin T. Effects of NASA Light Emitting Diode (LED) Irradiation on Wound Healing. J Clin Laser Med Surg. 2001;19:305-14.

28- White JM, Fagan MC, Goodis HE. Intrapulpal temperatures during pulsed Nd:YAG laser treatment of dentin, in vitro. J Periodontol. 1994;65:255-9.

29- Zach L, Cohen C. Pulp response to externally applied heat. Oral Surg Oral Med Oral Pathol.1965;19:515-30. 